$16^{\text {th }}$ International Conference on

AEROSPACE SCIENCES \& AVIATION TECHNOLOGY, ASAT - 16 - May 26 - 28, 2015, E-Mail: asat@ mtc.edu.eg Military Technical College, Kobry Elkobbah, Cairo, Egypt Tel : +(202) 24025292 - 24036138, Fax: +(202) 22621908

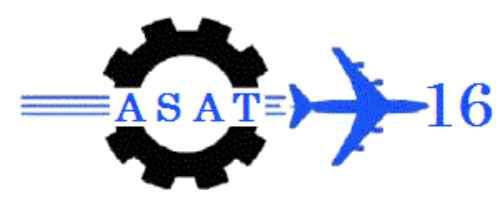

\title{
EXPERIMENTAL PROGRAM AND TESTING PROCEDURES TO CHECK THE CAPABILITY OF SOIL-RCSW COMBINATION IN PREVENTING GAS LEAKAGE
} FROM UNDERGROUND AEROSPACE GAS-FACILITIES Ahmed Konsowa ${ }^{1}$, Ayman Mosallam ${ }^{2}$, and Mohamed A. Barakat ${ }^{3}$

\begin{abstract}
Fukushima "I" nuclear accident (Japan 2011) has drawn attention to the issue of gas leakage from hazardous facilities through building boundaries, even if that facility was designed in order to prevent undesirable gas leakage from the building under the non-conventional operating conditions. In other words and as an example, the ventilation system for many types of hazardous facilities buildings, such as aerospace Hydrogen-facilities, provides a negative pressure gradient relative to their outside ambient atmospheric pressure. However, if an event such as an earthquake beyond the normal design basis occurs, both the shear wall structure and the facility itself may be damaged. Also, normal or extreme wind loading on the building will result in regions where the external pressure is less than the internal pressure, which may allow air leakage out of the structure.

From the foregoing semantics, the idea of this paper has come, to locate the hazardous facilities underground where possible, with developing their boundaries to perform as potential gas insulation.

The paper aims at developing a combination of soil and Reinforced Concrete Shear Walls (RCSW's) to perform as effective-potential gas insulation for underground aerospace facilities. It involves the configurations and procedures that were used in experimental verification tests to measure gas permeability of the proposed Soil-RCSW's Combination.
\end{abstract}

\section{1- INTRODUCTION}

This paper focuses on presenting the configurations of the tests conducted where leakage measurements were taken. [8]

The experimental program includes three parts. The first involves testing the RCSW specimens under four levels of lateral loading, representing four loading steps. The second involves applying an air leakage test using the Pressure Decay Method (PDM) at the ends of each load step. The third part involves applying the test using the same method after attaching varieties of soil specimens to the downstream side of the RCSW after two loading steps: load step 3 and load step 4, as shown herein while demonstrating the PDM.

1. Asst. Prof., Egyptian Armed Forces, Egypt

2. Professor, University of California, Irvine, USA

3. Assoc. Prof., Egyptian Armed Forces, Egypt 


\section{2- LATERAL LOADING TESTS}

\section{1- Specimens Description}

\subsection{1- RCSW Specimen}

One RCSW specimen was fabricated at the SETH Lab, UC Irvine [5], with design details comparable to [4]. The wall specimen was fabricated from a concrete mix using 0.75 in $(\approx 2 \mathrm{~cm})$ crushed rock aggregate with w/c ratio equals 0.39 and having a 28-day nominal compressive strength of $4 \mathrm{ksi}\left(\approx 281 \mathrm{~kg} / \mathrm{cm}^{2}\right)$. The physical structure consists of a $32 \times 48 \times 6$ in $\approx 81.3 \times 122 \times 15.2 \mathrm{~cm}$ (Height $\times$ Length $\times$ Thickness) shear wall, resulting in an aspect ratio of 0.30 . The region of interest was defined by the wall segment with a circular shape with a diameter 24 in $(\approx 61 \mathrm{~cm})$. The point of load application, $\boldsymbol{h}$, was 36 in $(91.5 \mathrm{~cm})$ above the point of base of the
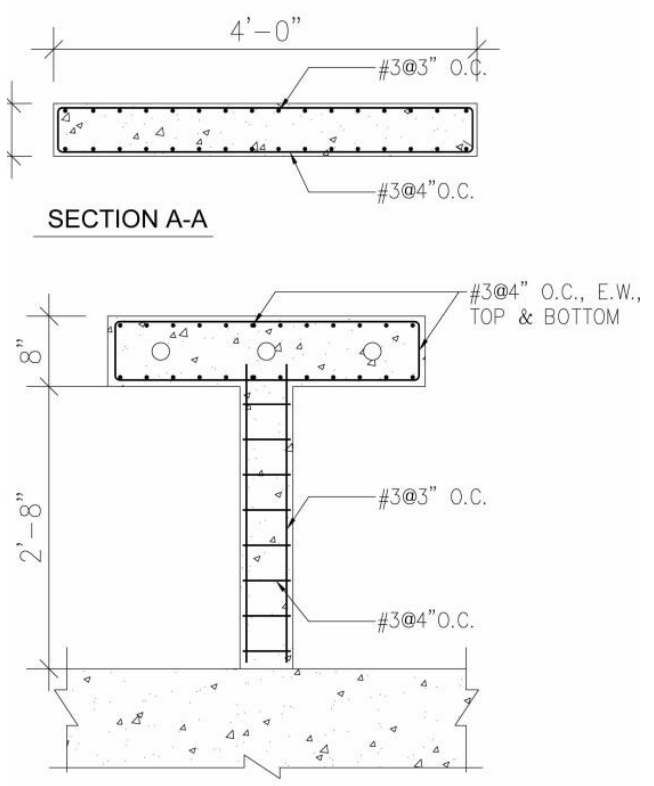

SECTION B-B

Figure 1: RCSW Specimen Section

wall.
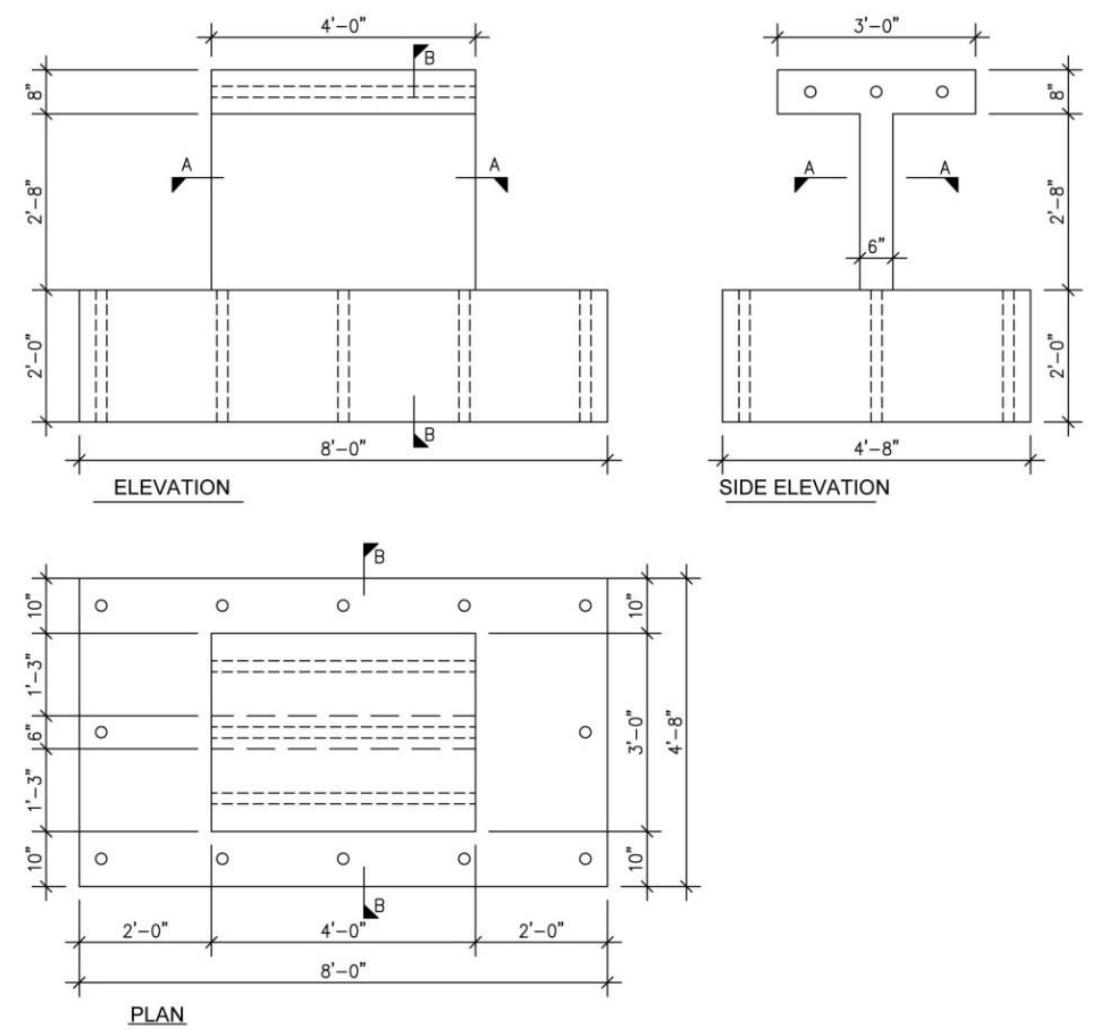

Figure 2: RCSW Specimen Dimensions
The wall itself was reinforced with CRSI D3 deformed steel reinforcing bars with nominal yield strength of $60 \mathrm{ksi}(\approx 4218$ $\left.\mathrm{kg} / \mathrm{cm}^{2}\right)$. These bars were placed in offset mats on each face of the wall, with vertical bars placed on 3 in $(7.62 \mathrm{~cm})$ on centers and horizontal bars placed at 4 in (10.16 $\mathrm{cm})$ on centers. One inch $(2.54 \mathrm{~cm})$ of minimum clear cover was provided to the reinforcing steel on all surfaces. Refer to Figure 1 for a schematic of the wall section and to Figure 2 for shear wall specimen detail. An overall view of the test configuration is shown in Figure 3 

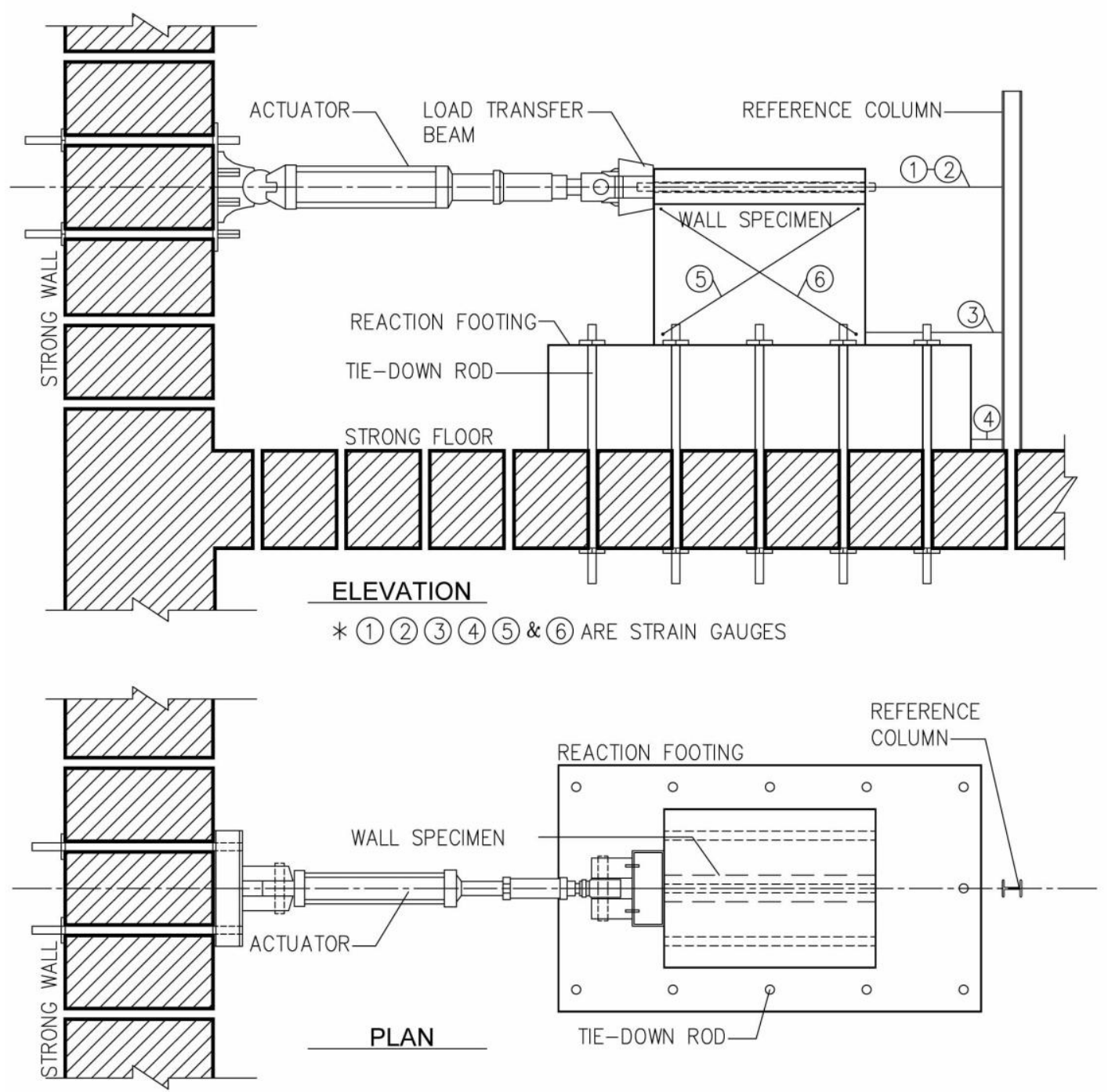

Figure 3: Test Configuration
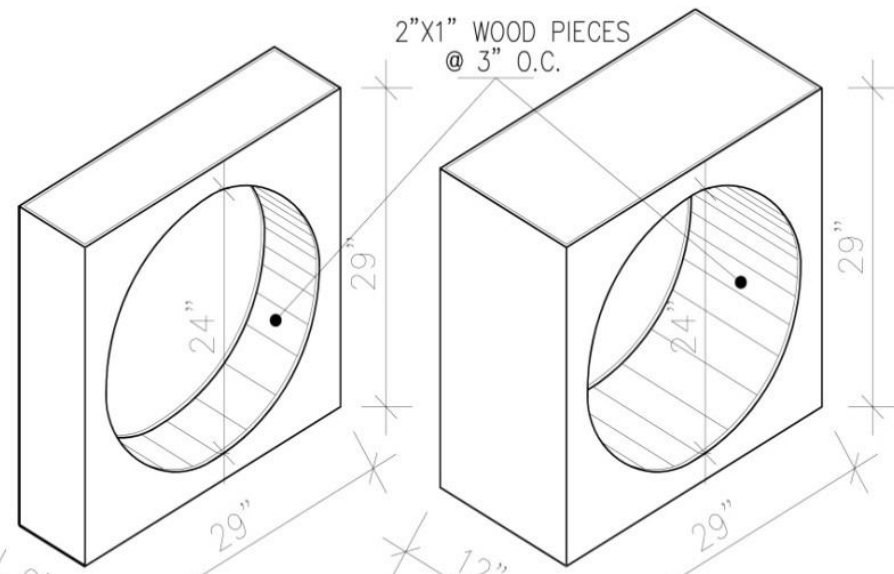

Figure 4: Soil Specimen Boxes' Shape and Size 


\subsection{2- Soil Specimens}

Eighteen soil combinations were divided into two sets of specimens, differentiated by the thickness, with nine soil combinations for each. The main component is dry sand with average grain size $<0.2$ in $(\approx 0.5 \mathrm{~cm})$ [12], to be put into two cylindrical volumes 24 in $(\approx 61 \mathrm{~cm})$ diameter configured into two boxes 29 in $\times 29$ in $(73.66 \times 73.66 \mathrm{~cm})$ with two values of thickness, 6 in $(15.24 \mathrm{~cm})$ and 12 in $(30.48 \mathrm{~cm})$, while using plastic mesh with too-narrow openings at both opened sides of the cylindrical volumes. Each specimen was consisted of sand with varied moisture content to be $25 \%, 50 \%$, and $75 \%$ of the saturation limit, and varied ratios of Fine Fraction content, $\mathrm{f}$ (grain size $<0.0025$ in $\approx 0.065 \mathrm{~mm}$ ), to be $\mathrm{f}<15 \%, 15 \%<\mathrm{f}<65 \%$, and $\mathrm{f}>65 \%$, with using fine ground silica of 40 micron $(0.0016$ in) grain-size as the fine fraction. Soil specimens' configurations are summarized in Table 1, and refer to Figure 4 and Figure 5 for soil specimen boxes' shape and size.

Table 1: Soil Specimens' Configurations

\begin{tabular}{|c|c|c|c|c|}
\hline Specimen & Grain size limits & $\begin{array}{l}\text { Specimen } \\
\text { Thickness }\end{array}$ & $\begin{array}{c}\text { Moisture } \\
\text { Content }\end{array}$ & $\begin{array}{c}\text { Fine-Fraction } \\
\text { Ratio (f) }\end{array}$ \\
\hline S1 & $0.01 "$ to $0.2 "$ & 6" & $25 \%$ & $10 \%$ \\
\hline $\mathrm{S} 2$ & $0.01 "$ to $0.2 "$ & $6 "$ & $25 \%$ & $50 \%$ \\
\hline 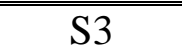 & $0.01 "$ to $0.2 "$ & $6 "$ & $25 \%$ & $75 \%$ \\
\hline S4 & $0.01 "$ to $0.2 "$ & $6 "$ & $50 \%$ & $10 \%$ \\
\hline S5 & $0.01 "$ to $0.2 "$ & $6 "$ & $50 \%$ & $50 \%$ \\
\hline S6 & $0.01 "$ to $0.2 "$ & $6 "$ & $50 \%$ & $75 \%$ \\
\hline S7 & $0.01 "$ to $0.2 "$ & $6 "$ & $75 \%$ & $10 \%$ \\
\hline S8 & $0.01 "$ to $0.2 "$ & $6 "$ & $75 \%$ & $50 \%$ \\
\hline S9 & $0.01 "$ to $0.2 "$ & $6 "$ & $75 \%$ & $75 \%$ \\
\hline S10 & $0.01 "$ to $0.2 "$ & $12 "$ & $25 \%$ & $10 \%$ \\
\hline S11 & $0.01 "$ to $0.2 "$ & $12 ”$ & $25 \%$ & $50 \%$ \\
\hline S12 & $0.01 "$ to $0.2 "$ & $12 \%$ & $25 \%$ & $75 \%$ \\
\hline S13 & $0.01 "$ to $0.2 "$ & $12 "$ & $50 \%$ & $10 \%$ \\
\hline S14 & $0.01 "$ to $0.2 "$ & $12 ”$ & $50 \%$ & $50 \%$ \\
\hline S15 & $0.01 "$ to $0.2 "$ & $12 "$ & $50 \%$ & $75 \%$ \\
\hline S16 & $0.01 "$ to $0.2 "$ & $12 "$ & $75 \%$ & $10 \%$ \\
\hline S17 & $0.01 "$ to $0.2 "$ & $12 "$ & $75 \%$ & $50 \%$ \\
\hline S18 & $0.01 "$ to $0.2 "$ & $12 "$ & $75 \%$ & $75 \%$ \\
\hline
\end{tabular}




\subsection{3- Soil-RCSW Combination Specimens}

Four $1 \frac{1}{2} \times 1 \frac{1}{2}$ in $(3.81 \times 3.81$ $\mathrm{cm})$ UNISTRUT angles and four $1 / 2$ in $(1.27 \mathrm{~cm})$ diameter threaded rods were used to attach the gas chamber and the boxes of soil specimens to the RCSW, with using a glue-gun to seal at the touch-line. Figure 6 shows the combination of soil specimen, gas chamber, and RCSW specimen to be used in the gas leakage experiment tests.

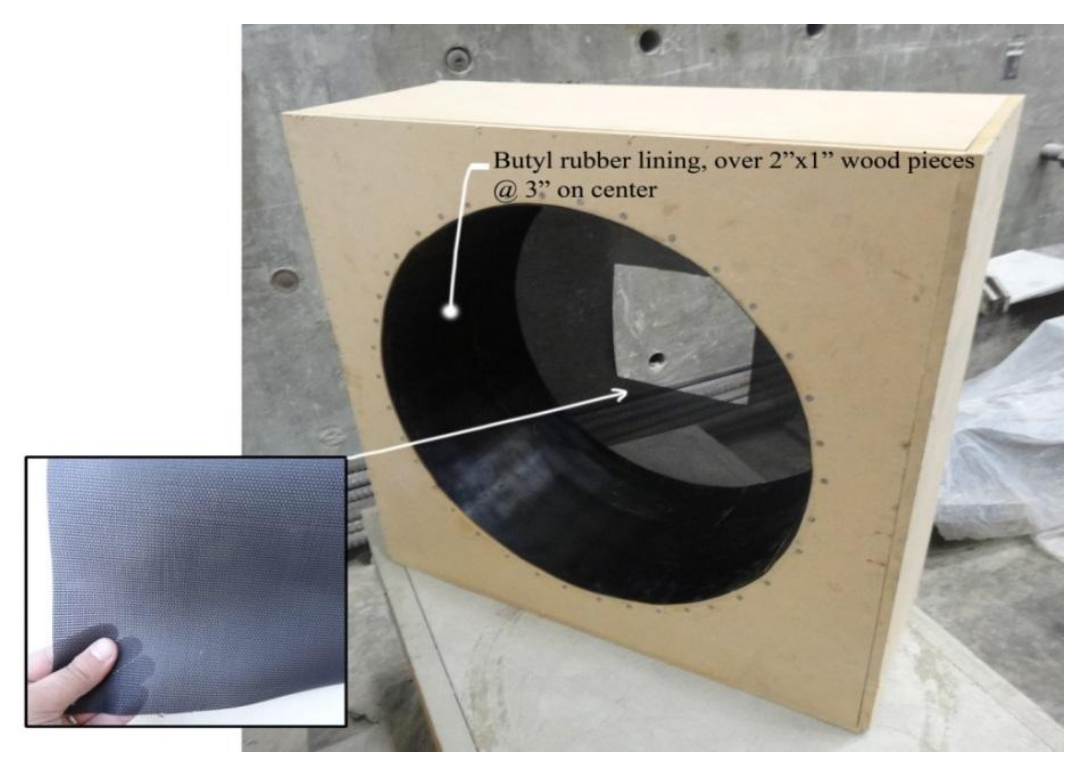

Figure 5: Soil Specimen Boxes' Configurations

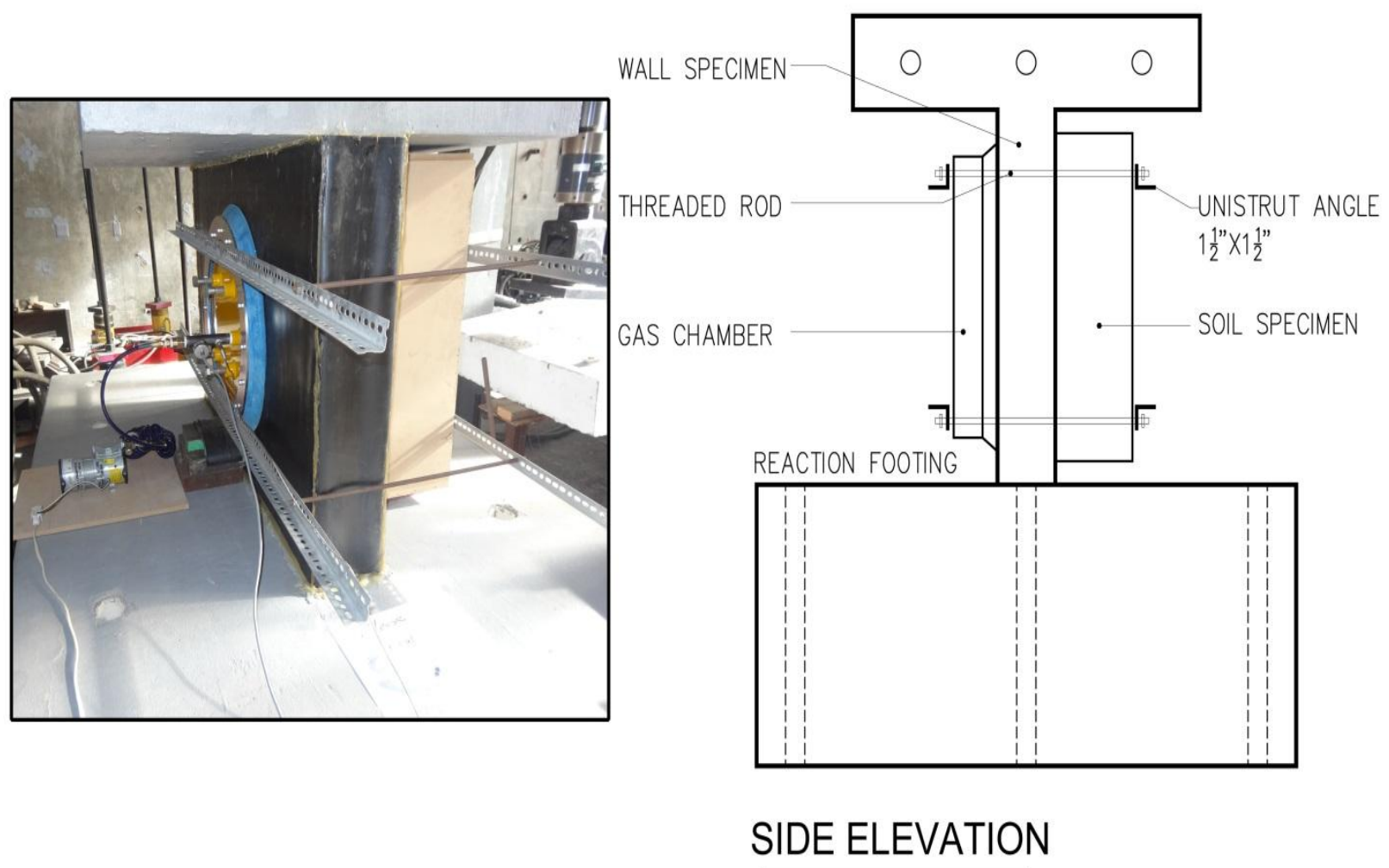

Figure 6: RCSW-Soil Combination Specimens 


\section{2- Experimental Setup}

The specimen was fixed to the strong floor using 10 tie-down rods (Dywidags). MTS actuator with a capacity of 250 kips $(\approx 1112 \mathrm{kN})$ was used to apply lateral loads to the top of the specimen, resulting in a cantilever loading configuration. The actuator was horizontally installed to the strong wall using four $1 \frac{1 / 4}{4}$ in $(3.18 \mathrm{~cm})$ diameter connecting bolts, and was used in a loadcontrolled cycles, as illustrated in Figure 3.

\section{3- Specimens Instrumentation}

As shown in Figure 3, and as implemented by [16], a reference column was attached to the strong floor to measure the top deformation relative to the bottom of the specimen. Two Linear Variable Displacement Transducers (LVDT's) 1 and 2 were used, one on the upstream side, and the other on the downstream side, to reduce the test error introduced by the torsional deformation in the test. LVDT's 3 and 4 were used to measure the slip between the specimen and the footing, and between the footing and the strong floor, respectively. LVDTs 5 and 6 were used to measure the diagonal deformation of the specimen. In total, ten channels of data acquisition were used.

\section{4- Specimens Preparation}

\subsection{1- RCSW Specimen Preparation}

To ensure that air traveled primarily thru a defined region of interest, each wall was wrapped with $1 / 16$ in $(0.16 \mathrm{~cm})$ thick Butyl rubber liner. The rubber was attached to the concrete using STABOND-0836 adhesive, and was cut to expose the concrete within the circular region of interest after being wrapped. After the main body of the specimen had been wrapped, the top and bottom were sealed with silicon caulking creating a leak tight specimen similar to what was implemented by [13]. An annotated sequence of the wrapping procedure for the RCSW is shown in Figure 7. 


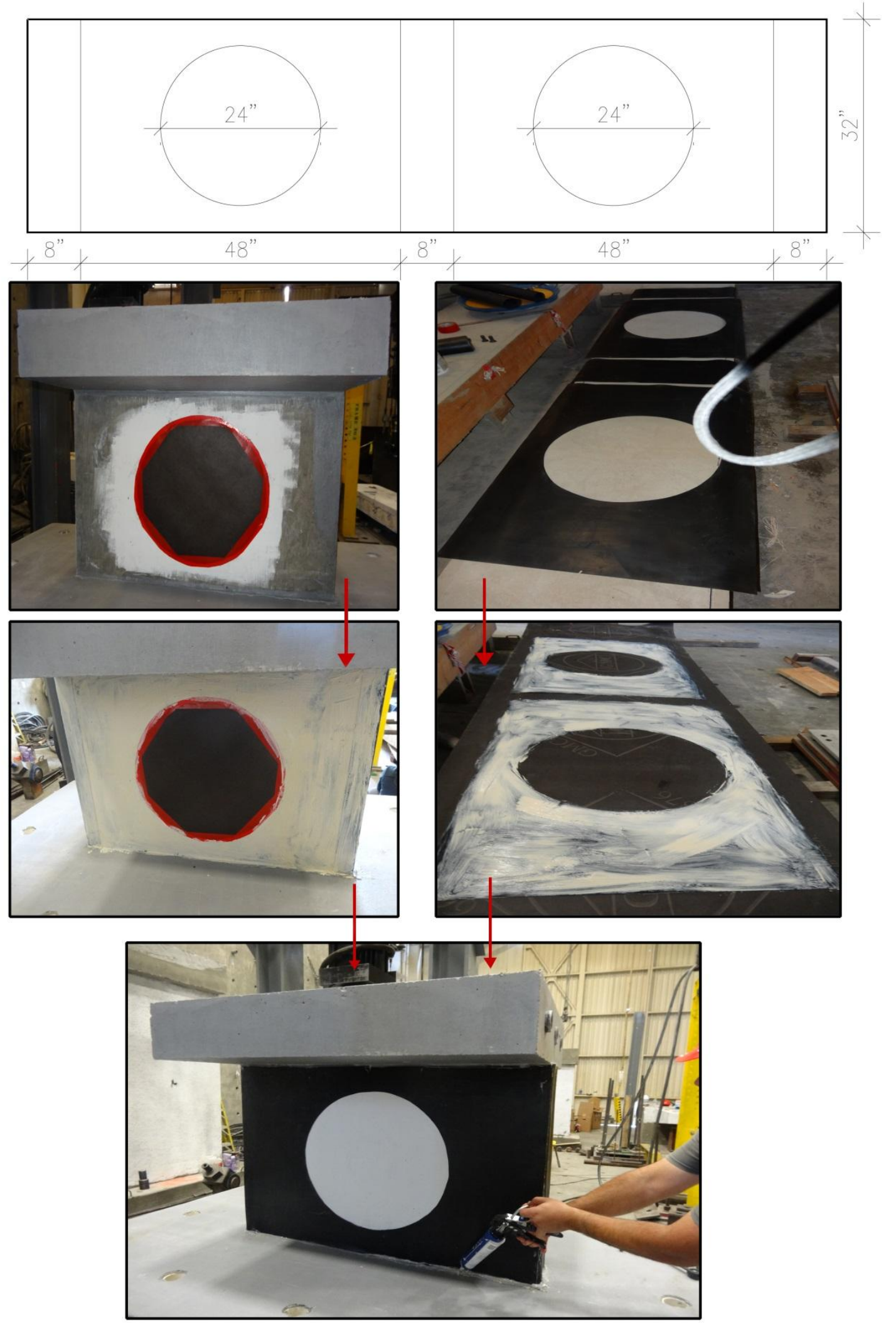

Figure 7: Wrapping Procedures for RCSW 


\subsection{2- Soil Specimens Preparation}

Figure 8 represents the preparation procedures for the soil specimens.

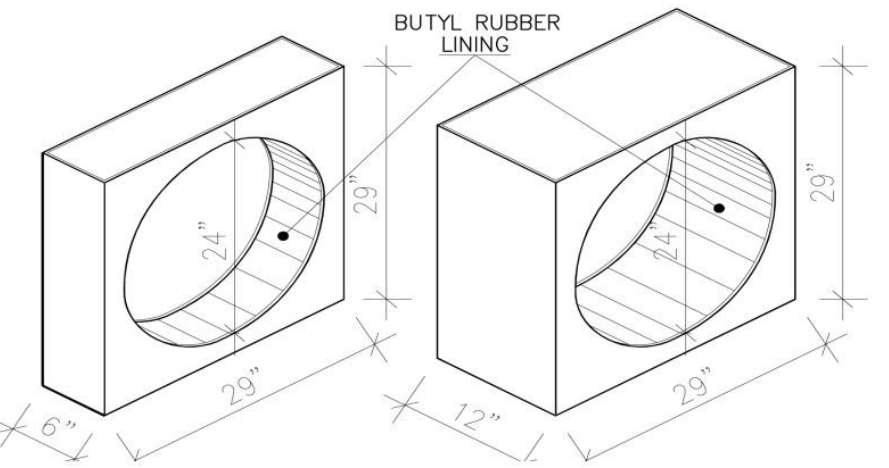

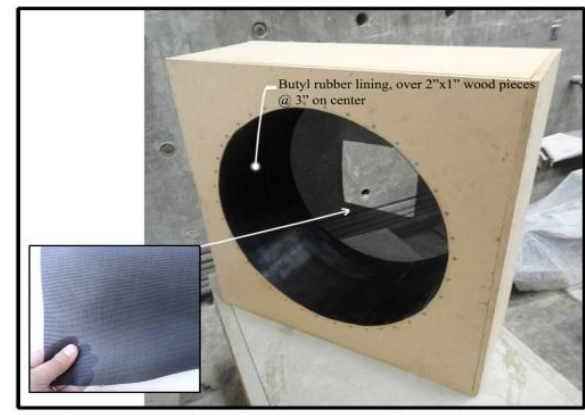

1- Line the cylinder's inner surface with butyl rubber, and clad its 2 faces with plastic mesh with too-narrow openings, while leaving an opening 8 " 8 " to be used in putting/changing the sand

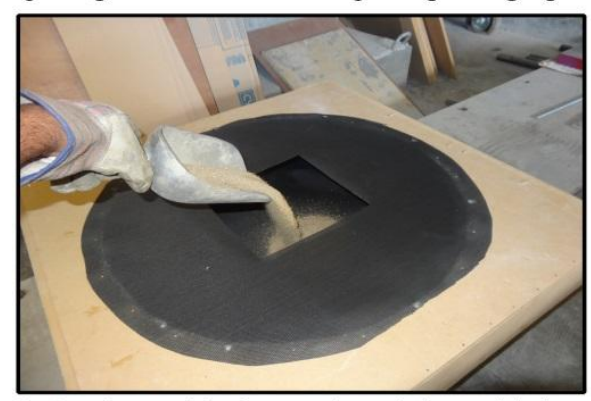

3- Put the sand in the specimen's box with the required fine-fraction content (fine ground silica)

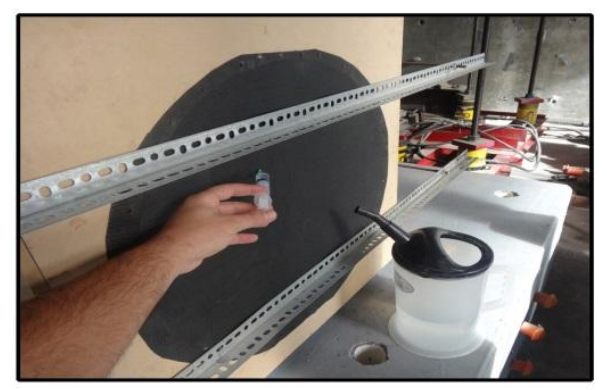

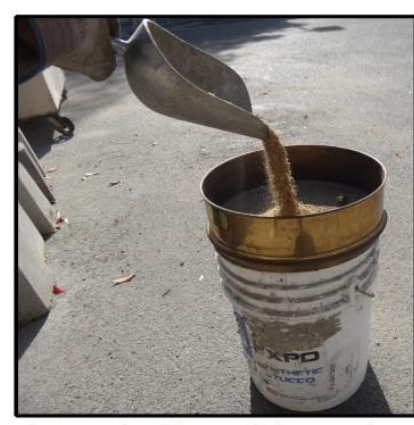

2- Use the Sieve of the opening size: 0.2 " to obtain the sand of the required grain size.

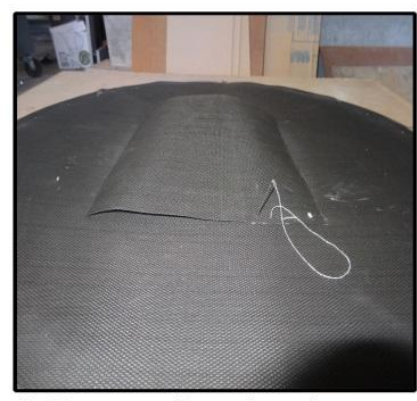

4- Use a needle and crank to close the cylinder's opening

5- Use a syrenge and a graded pot to increase the moisture content when needed

Figure 8: Soil Specimens Preparations 


\section{5- Lateral Loading}

In the experiment, compatibly with what has been recommended by [3] and American Concrete Institute (ACI) loading protocol (2011) [17], and similar to what was implemented by [4], [5], [13], [16], lateral demand input involved quasi-static load controlled reversed cyclic input applied in a cantilever fashion. Initially, four prescribed load controlled amplitudes were applied with three cycles to each target amplitude. Load controlled amplitudes of $25 \%, 50 \%$, $75 \%$, and $100 \%$ of the design strength $\left(\varnothing V_{n}\right)$ were used.

According to ACI 318-11 (2011), Ø $V_{n}$ of RCSW could be estimated as: [17]

$$
\varnothing V_{n=} \varnothing A_{c v}\left(\alpha_{c} \sqrt{f^{\prime} c}+p_{n} f_{y}\right)
$$

where: $\boldsymbol{V}_{\boldsymbol{n}}$ is the nominal shear strength of the wall, $\varnothing$ is the strength reduction factor, which is taken as 0.75 for shear, $\boldsymbol{A}_{\boldsymbol{c}}$ is the gross area of concrete section bounded by the wall thickness and length of the section in the direction of shear force considered, $\boldsymbol{\alpha}_{c}$ is a coefficient defining the relative contribution of the concrete strength to the wall shear strength, which is equal to 3.0 for walls with aspect ratios $\leq 1.5$, and $\boldsymbol{f}_{c}{ }_{c}$ and $\boldsymbol{f}_{\boldsymbol{y}}$ are the strength of the concrete and the used reinforcing steel, respectively. $\boldsymbol{p}_{\boldsymbol{n}}$ is the ratio of area of distributed reinforcement parallel to the plane of $\boldsymbol{A}_{\boldsymbol{c}}$ to the gross concrete area perpendicular to that reinforcement. In this case, 2-\#3 bars at 4 in $(10.16 \mathrm{~cm})$ o.c. were used, therefore $\boldsymbol{p}_{\boldsymbol{n}}=2 \times 0.11 /(4 \times 6)=0.91 \%$. Accordingly, $\varnothing V_{n}$ was calculated as $158.9 \mathrm{kip}(706.8 \mathrm{kN})$. So, load controlled amplitudes of $25 \%, 50 \%, 75 \%$, and $100 \%$ of the design strength $\left(\varnothing V_{n}\right)$ were found to be 40, 80, 120, and 160 kip $(177.93,355.86,533.79$, and $711.72 \mathrm{kN}$ ) respectively.

\section{6- RCSW Specimen Damage Documentation}

To document the evolution of damage during testing, a systematic procedure was adopted that consists of taking photographs, mapping cracks, and measuring crack properties. Prior to each test, photographs of the specimen were taken. Photographs were also taken following each loading step. Once the first crack formed, a crack map was manually drawn and the crack length, width and spacing were recorded for that displacement step and every additional displacement step.

\section{3- AIR FLOW TESTING SETUP}

The Pressure Decay Method (PDM) was used to measure the permeability $\boldsymbol{k}$ of each specimen. Knowing that at the greatest drift ratios the crack widths greatly increased to the point at which a vacuum could not be created, thus PDM couldn't be used at these drift ratios. 


\section{1- Pressure Decay Method}

PDM is simply to pressurize one side of the wall, henceforth the "upstream" side, and permit the pressure to decay by permeation through the uncoated RCSW to the "downstream" side, which was maintained at atmospheric pressure, and to have the soil specimen attached to it. It was used to measure the permeability of the RCSW specimen first, and then the permeability of the SoilRCSW Combination specimens at the conclusion of loading steps 3 and 4, as noted in Figure 9. In these experiments, the upstream chamber was pressurized to about $2.0 \mathrm{psi}(13.79 \mathrm{kPa})$ plus to the atmospheric pressure, which is the possible maximum differential pressure in Special Nuclear Material Laboratory (SNML) at Los Alamos national laboratory [3], and allowed to decay to atmospheric pressure. The permeability coefficient through RCSW $k_{D}\left(\right.$ in $\left.^{2}\right)$, defined by [4] may be found as:

$$
k=\frac{2 \mu L V T_{m}}{A \cdot \Delta t\left(p_{m}^{2}-p_{a t m^{2}}{ }^{2}\right.}\left(\frac{P_{t}}{T_{t}}-\frac{P_{t+\Delta t}}{T_{t+\Delta t}}\right)
$$

where: $\mu=\left(5.672 \times 10^{-5} . \mathrm{T}+0.0338\right) \times 10^{-5} \mathrm{lb} . \mathrm{s} / \mathrm{ft}^{2}$

$\boldsymbol{A}$ is the cross-sectional area perpendicular to the flow direction $\left(\mathrm{in}^{2}, \mathrm{~cm}^{2}\right) ; \boldsymbol{L}$ is the thickness of the wall (in, $\mathrm{cm}$ ); $\boldsymbol{V}$ is the pressurized volume of gas $\left(\mathrm{in}^{3}, \mathrm{~cm}^{3}\right) ; \boldsymbol{\mu}$ is the dynamic viscosity (lb.s/ $\mathrm{ft}^{2}$, Pa.s), given by Equation 3, as a function of temperature $\boldsymbol{T}\left({ }^{\circ} \mathrm{F}\right) ; \boldsymbol{t}$ is the time interval (seconds) between the two measurements; $\boldsymbol{T}$ is the absolute temperature $\left({ }^{\circ} \mathrm{R}\right) ; \boldsymbol{P}$ is the absolute pressure (psi, Pa); $\boldsymbol{P}_{\boldsymbol{m}}$ is the mean value of the measurements between time $\mathrm{t}$ and time $\mathrm{t}+\Delta t ; \boldsymbol{T}_{\boldsymbol{m}}$ is the temperature at $\mathrm{P}_{\mathrm{m} ;}$ and $\boldsymbol{P}_{\text {atm }}$ is the absolute atmospheric pressure (psi, $\mathrm{Pa}$ ). [3]

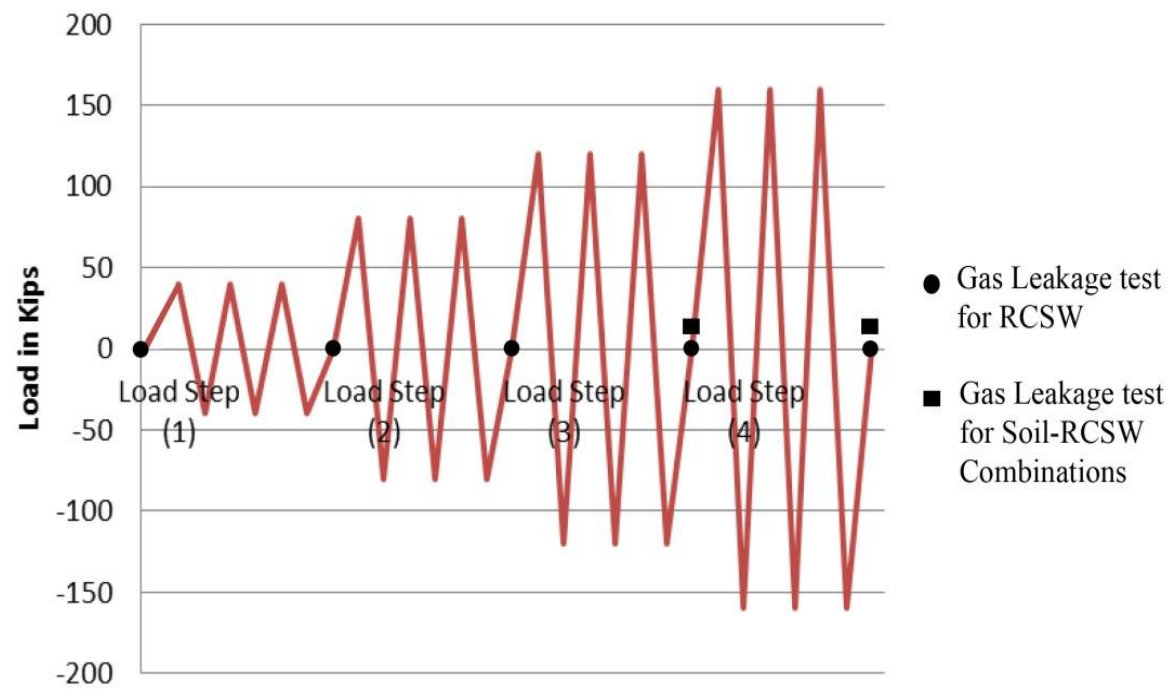

Figure 9: Loading Protocol and Gas-Leakage Tests 


\section{2- Gas Leakage Experimental Setup}

The Pressure Decay Test (PDT) setup used for the testing is shown in Figure 10. To facilitate the evaluation and the comparison between the different permeability behaviors of the RCSW specimen under the various load steps, a setup similar to what has been implemented by [13] on his nine RCSW's was followed. The setup consists of a suction cup, vacuum pump, two pressure transducers, a thermocouple, six displacement transducers, and reference column.

The suction cup used for the test was an "ANVER" industrial suction cup (Model VP235Q) as shown in Figure 11. The suction cup diameter is 24 in $(61 \mathrm{~cm})$ and it has a vacuum capacity of $10 \mathrm{psi}(68.95 \mathrm{kPa})$. It came with a single $3 / 4$ in $(1.9 \mathrm{~cm})$ female NPT port, which was used to apply and measure the vacuum applied to the wall thru $3 / 4$ in $(1.9 \mathrm{~cm})$ steel pipe, with 6 in $(15.24$ $\mathrm{cm})$ length, that has an additional two $1 / 4$ in $(0.64 \mathrm{~cm})$ female NPT ports to attach a temperature transducer that was used to record temperature, and a pressure transducer that was used to record pressure, within the vacuum chamber. See Figure 10 for the suction cup setup.

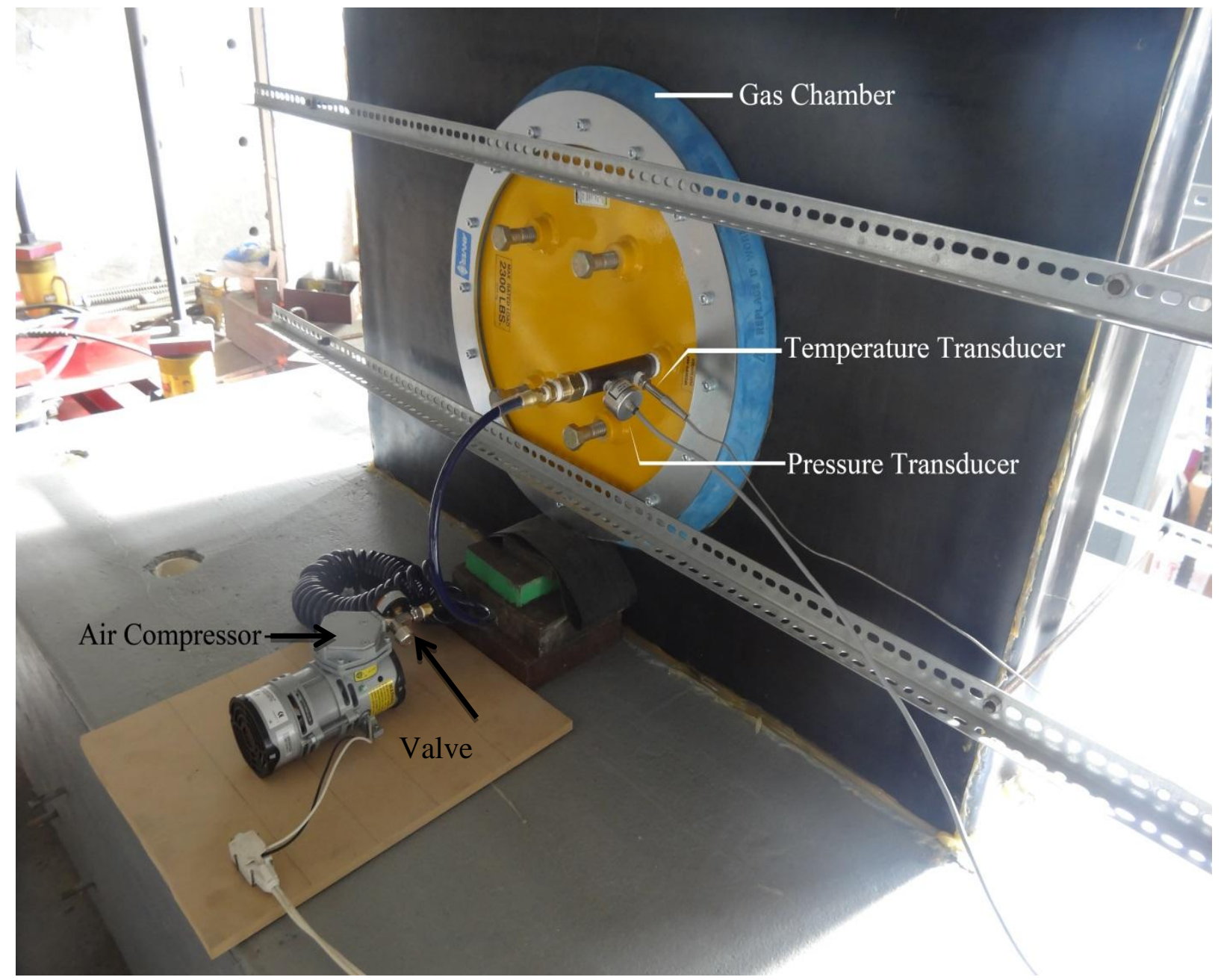

Figure 10: Pressure Decay Test Setup 

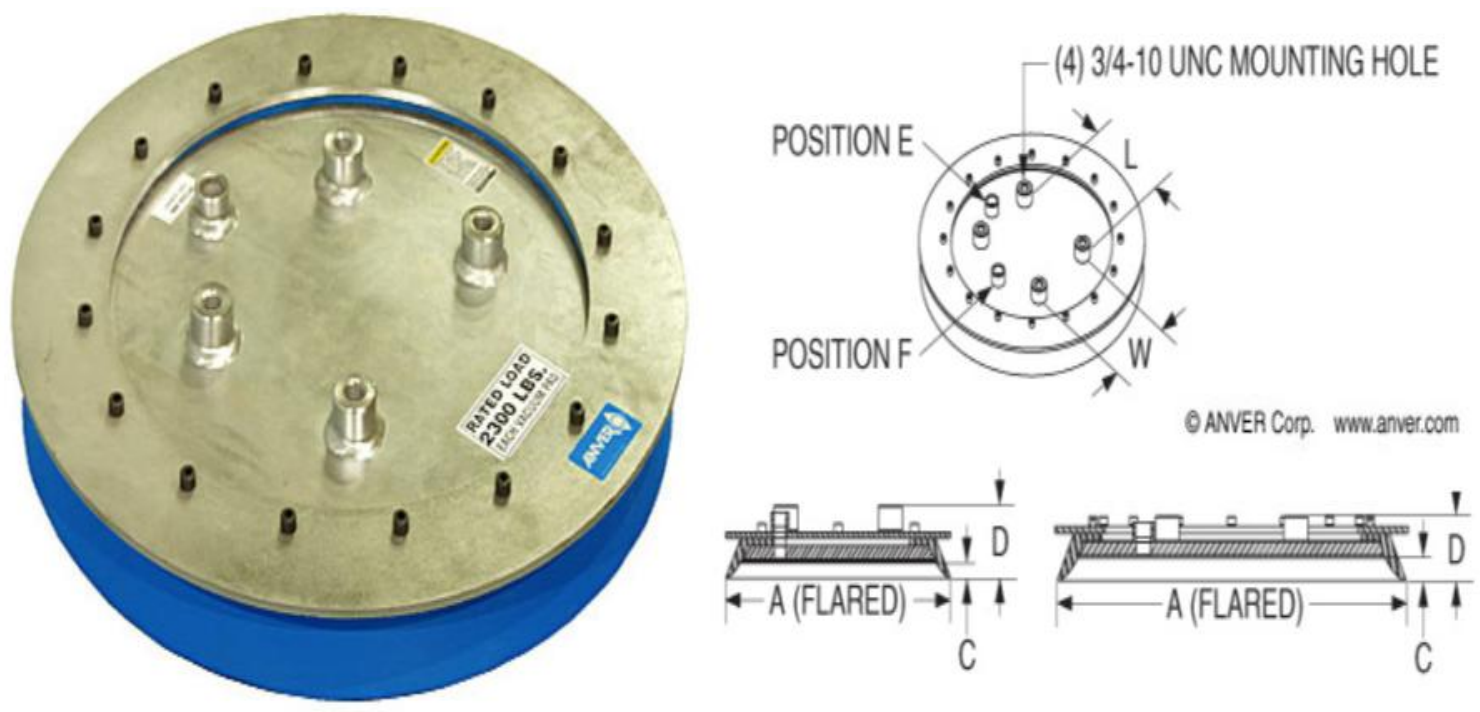

Figure 11: ANVER Suction Cup used for PDT

Source: http://www.anver.com

\section{3- Instrumentation}

Both pressure transducers used for the pressure decay tests were "OMEGA" brand transducers. The pressure transducer used to measure vacuum pressure within the suction cup was Omega model PX177-025AI. Also the second pressure transducer, which was used to measure atmospheric pressure, was the same OMEGA model PX177-025AI. Both transducers could measure pressures from 0 to 25 psia $(172.37 \mathrm{~Pa})$.

The thermocouple used was an OMEGA model number TC-K- 1/8 NPT-G-72. The thermocouple was calibrated to two points using ice water and boiling water. The vacuum pump used for the test was GAST model M0A-V133-AE. The pump's air flow capacity is $0.8 \mathrm{cfm}$ $\left(0.023 \mathrm{~m}^{3} / \mathrm{min}\right)$ at a maximum vacuum of $12 \mathrm{psia}(82.74 \mathrm{kPa})$.

Three channels of data acquisition were used to record pressure and temperature measurements. During the PDT, data was collected at an increment of pressure change of 0.01 psi (68.95 Pa), while adopting the mean values in calculations.

\section{4- CONCLUSION}

This paper involves large-scale experimental verification tests of different Soil-RCSW Combination specimens with different soil characteristics such as thickness, fine fraction content, and moisture content. The ultimate goal of the study is to develop a reliable technical solution that almost prevents gas leakage from underground nuclear fuel facilities, or any similar hazardous facilities.

The paper provides the experimental program and test procedures to check the applicability of the developed Soil-RCSW Combination to be functioned as potential gas insulation for underground nuclear facilities, so as to be enveloped with the combination where necessary. 


\section{5- ACKNOWLEDGEMENT}

The Authors would like to thank the Egyptian Armed Forces for their financial support to the first author during the experimental work of this research. Also, the support of SETH-Lab crew at Henry Samueli School of Engineering, University of California, Irvine (UCI) is gratefully acknowledged.

\section{6- REFERENCES}

1. Billard, Y., Debicki, G., and Coudert, L. (2005). "Leakage rate through a non-cracked concrete wall, comparison between two situations: Air pressure test and accident conditions". Nuclear engineering and design, 235(17), 2109-2123.

2. DiGiulio, D. (2007). "Single-interval gas permeability testing", the 17th Annual Association for Environmental Health and Sciences (AEHS) Meeting, San Diego, (USA)

3. Farrar, C. R., Bennett, J. G., Dunwoody, W. E., and Baker, W. E. (1989). "Static load cycle testing of a low-aspect-ratio six-inch wall TRG-type structure" TRG-4-6 (1. 0, 0. 25) (No. NUREG/CR-5222; LA-11422-MS). Nuclear Regulatory Commission, Washington, DC (USA). Div. of Engineering; Los Alamos National Lab., NM (USA).

4. Girrens, S. P. and Farrar, C. R. (1991). "Experimental assessment of air permeability in a concrete shear wall subjected to simulated seismic loading", Los Alamos National Laboratory, NM, (USA)

5. Hamilton, C. H., Hutchinson, T. C., Pardoen, G. C., Salmon, M. W., and Wang, T. (2004). "Gas and aerosol leakage rate through reinforced concrete shear walls: Experimental study", 13th World Conference on Earthquake Engineering, Vancouver, B.C., Canada, Paper:2484

6. Hutchinson, T. C. and Soppe T. E. (2011). "Experimentally measured permeability of uncracked and cracked concrete components", Journal of Materials in Civil Engineering 24.5, 548-559.

7. Hutchinson, T.C. and Wang, T. (2006). "Sensitivity of flow rate prediction through low aspect ratio reinforced concrete shear walls due to variable mesh selection", Journal of Nuclear Engineering and Design (236), 1029-1038.

8. Konsowa, A., "Applying a Potential Gas Insulation Using Reinforced Concrete Walls for Underground Nuclear Facilities", PhD. Dissertation, Civil and Environmental Engineering Department, University of California, Irvine (UCI), USA, 2014

9. Mahaffey J.A. (2012). "Nuclear Accidents and Disasters", Facts on File, Inc., (USA)

10. Riva, P., Brusa, L., Contri, P., and Imperato, L. (1999). "Prediction of air and steam leak rate through cracked reinforced concrete panels". Nuclear engineering and design, 192(1), 13-30. 
11. Rizkalla, S. H., Lau, B. L., and Simmonds, S. H. (1984). "Air leakage characteristics in reinforced concrete", Journal of Structural Engineering 110.5, 1149-1162.

12. Saiyouri, N., Bouasker, M., and Khelidj, A. (2008). "Gas permeability measurement on injected soils with cement grout", Journal of Cement and Concrete Research (38), 95103.

13. Soppe, T. E. (2009). "Experimental damage-gas flow correlations for cyclically loaded reinforced concrete walls.", Ph.D. Dissertation, University of California, San Diego, (USA)

14. Soppe, T. E., and Hutchinson, T. C. (2011). "Assessment of gas leakage rates through damaged reinforced-concrete walls", Journal of Materials in Civil Engineering, 24(5), $560-567$.

15. Tinkler, J., Del Frate, R., and Rizkalla, S. (1987). "The prediction of air leakage rates through cracks in pressurized reinforced concrete containment vessels", The International Journal of Pressurized Vessels and Piping (29), 33-46.

16. Wang, T., (2008). "Gas leakage rate through low aspect ratio reinforced concrete shear walls", Ph.D. Dissertation, University of California, Irvine, (USA)

17. ACI 318-11 (2011). "Building code requirements for structural concrete" (ACI 318-11) and commentary (ACI 318R-02). American Concrete Institute, Detroit, MI. (USA)

18. ASCE/SEI 7-05 (2005). "Minimum design loads for buildings and other structures", American Society of Civil Engineers.

19. DOE-STD-1020-2002 (2002). "Natural phenomena hazards design and evaluation criteria of energy facilities", U.S. Department of Energy, Washington, D.C., (USA)

20. FEMA 461 (2007). "Interim testing protocols for determining the seismic performance characteristics of structural and nonstructural components". Applied Technology Council, Redwood City, CA., (USA)

21. NASA (2005). "Safety standards for hydrogen and hydrogen systems". Office of safety and mission assurance, Washington D.C., (USA) 